University of Nebraska - Lincoln

DigitalCommons@University of Nebraska - Lincoln

Faculty Publications, Department of Child, Youth, and Family Studies

Child, Youth, and Family Studies, Department of

$7-1-2003$

\title{
Child Care Quality Matters: How Conclusions May Vary With Context
}

John M. Love

Mathematica Policy Research

Linda Harrison

Charles Sturt University

Abraham Sagi-Schwartz

University of Haifa

Marinus $\mathrm{H}$. van IJzendoorn

Leiden University

Christine Ross

Mathematica Policy Research

See next page for additional authors

Follow this and additional works at: https://digitalcommons.unl.edu/famconfacpub

Part of the Family, Life Course, and Society Commons

Love, John M.; Harrison, Linda; Sagi-Schwartz, Abraham; van IJzendoorn, Marinus H.; Ross, Christine; Ungerer, Judy A.; Raikes, Helen; Brady-Smith, Christy; Boller, Kimberly; Brooks-Gunn, Jeanne; Constantine, Jill; Kisker, Ellen Eliason; Paulsell, Diane; and Chazan-Cohen, Rachel, "Child Care Quality Matters: How Conclusions May Vary With Context" (2003). Faculty Publications, Department of Child, Youth, and Family Studies. 41.

https://digitalcommons.unl.edu/famconfacpub/41

This Article is brought to you for free and open access by the Child, Youth, and Family Studies, Department of at DigitalCommons@University of Nebraska - Lincoln. It has been accepted for inclusion in Faculty Publications, Department of Child, Youth, and Family Studies by an authorized administrator of DigitalCommons@University of Nebraska - Lincoln. 


\section{Authors}

John M. Love, Linda Harrison, Abraham Sagi-Schwartz, Marinus H. van IJzendoorn, Christine Ross, Judy A. Ungerer, Helen Raikes, Christy Brady-Smith, Kimberly Boller, Jeanne Brooks-Gunn, Jill Constantine, Ellen Eliason Kisker, Diane Paulsell, and Rachel Chazan-Cohen 
Published in Child Development 74:4 (July/August 2003), pp. 1021-1033. Copyright ( 2003 by the Society for Research in Child Development, Inc. Published by Blackwell Publishing, Inc. DOI 0009-3920/2003/7404-0004 Used by permission.

"This article may not exactly replicate the final version published in the SRCD journal. It is not the copy of record."

\title{
Child Care Quality Matters: How Conclusions May Vary With Context
}

\author{
John M. Love, Linda Harrison, Abraham Sagi-Schwartz, Marinus H. van IJzendoorn, Christine Ross, \\ Judy A. Ungerer, Helen Raikes, Christy Brady-Smith, Kimberly Boller, Jeanne Brooks-Gunn, \\ Jill Constantine, Ellen Eliason Kisker, Diane Paulsell, and Rachel Chazan-Cohen*
}

\begin{abstract}
Three studies examined associations between early child care and child outcomes among families different from those in the National Institute of Child Health and Human Development (NICHD) Early Child Care Research Network study. Results suggest that quality is an important influence on children's development and may be an important moderator of the amount of time in care. Thus, the generalizability of the NICHD findings may hinge on the context in which those results were obtained. These studies, conducted in three national contexts, with different regulatory climates, ranges of child care quality, and a diversity of family characteristics, suggest a need for more complete estimates of how both quality and quantity of child care may influence a range of young children's developmental outcomes.
\end{abstract}

\footnotetext{
*John M. Love, Mathematica Policy Research; Linda Harrison, Charles Sturt University; Abraham Sagi-Schwartz, University of Haifa; Marinus H. van IJzendoorn, Leiden University; Christine Ross, Mathematica Policy Research; Judy A. Ungerer, Macquarie University; Helen Raikes, Society for Research in Child Development visiting scholar, Administration for Children and Families, U.S. Department of Health and Human Services; Christy Brady-Smith, Columbia University; Kimberly Boller, Mathematica Policy Research; Jeanne Brooks-Gunn, Columbia University; Jill Constantine, Ellen Eliason Kisker, and Diane Paulsell, Mathematica Policy Research; Rachel Chazan-Cohen, Administration for Children and Families, U.S. Department of Health and Human Services.

Harrison and Ungerer of the Sydney Family Development Project gratefully acknowledge the contributions made by Brent Waters and Bryanne Barnett in designing the Sydney Family Development Project, and the continual inspiration provided by Robyn Dolby. The research was supported by grants from the Australian National Health and Medical Research Council, the Australian Research Council, Macquarie University, University of New South Wales, and The University of Melbourne. Writing was supported by grants from Charles Sturt University.

Sagi-Schwartz and van IJzendoorn of the Combined Haifa-National Institute of Child Health and Human Development (NICHD) Studies gratefully acknowledge the following support: The data on child center care in the United States were derived from the data set made available by the NICHD Early Child Care Research Network supported by NICHD through a cooperative agreement that calls for scientific collaboration between the grantees and the NICHD staff. We are grateful to Sarah Friedman for her support. Pieter Kroonenberg and Marielle Linting helped prepare the data for analysis. The contribution of Marinus van IJzendoorn was supported by a grant from the Dutch Ministry of Social Affairs and Employment to the NCKO (Dutch Consortium for Research in Child Care). The contribution of Abraham Sagi-Schwartz was supported by the dean of research at the University of Haifa.

The Early Head Start findings reported here are based on research conducted as part of the national Early Head Start Research and Evaluation Project funded by the Administration for Children and Families (ACF), U.S. Department of Health and Human Services under contract 105-95-1936 to Mathematica Policy Research, Princeton, NJ, and Columbia University's Center for Children and Families, Teachers College, in conjunction with the Early Head Start Research Consortium. The consortium consists of representatives from 17 programs participating in the evaluation, 15 local research teams, the evaluation contractors, and Administration on Children, Youth, and Families. Research institutions in the consortium (and principal researchers) include ACF (Rachel Chazan-Cohen, Judith Jerald, Esther Kresh, Helen Raikes, and Louisa Tarullo); Catholic University of America (Michaela Farber, Lynn Milgram Mayer, Harriet Liebow, Christine Sabatino, Nancy Taylor, Elizabeth Timberlake, and Shavaun Wall); Columbia University (Lisa Berlin, Christy Brady-Smith, Jeanne Brooks-Gunn, and Allison Sidle Fuligni); Harvard University (Catherine Ayoub, Barbara Alexander Pan, and Catherine Snow); Iowa State University (Dee Draper, Gayle Luze, Susan McBride, Carla Peterson); Mathematica Policy Research (Kimberly Boller, Jill Constantine, Ellen Eliason Kisker, John M. Love, Diane Paulsell, Christine Ross, Peter Schochet, Cheri Vogel, and Welmoet van Kammen); Medical University of South Carolina (Richard Faldowski, Gui-Young Hong, and Susan Pickrel); Michigan State University (Hiram Fitzgerald, Tom Reischl, and Rachel Schiff-man); New York University (Mark Spellmann and Catherine Tamis LeMonda); University of Arkansas (Robert Bradley, Mark Swanson, and Leanne Whiteside-Mansell); University of California, Los Angeles (Carollee Howes and Claire Hamilton); University of Colorado Health Sciences Center (Robert Emde, Jon Korfmacher, JoAnn Robinson, Paul Spicer, and Norman Watt); University of Kansas (Jane Atwater, Judith Carta, and Jean Ann Summers); University of Missouri-Columbia (Mark Fine, Jean Ispa, and Kathy Thornburg); University of Pittsburgh (Beth Green, Carol McAllister, and Robert McCall); University of Washington School of Education (Eduardo Armijo and Joseph Stowitschek); University of Washington School of Nursing (Kathryn Barnard and Susan Spieker); and Utah State University (Lisa Boyce and Lori Roggman). The content of this publication does not necessarily reflect the views or policies of the Department of Health and Human Services, nor does mention of trade names, commercial products, or organizations imply endorsement by the U.S. government.

Correspondence concerning this article should be addressed to John M. Love, Mathematica Policy Research, 600 Alexander Park, Princeton, NJ 08540 (609-275-2245); to Linda Harrison, School of Teacher Education, Charles Sturt University, Bathurst, NSW 2795, Australia (612-63384872); and to Abraham Sagi-Schwartz, Center for the Study of Child Development, University of Haifa, 6035 Rabin Complex, Haifa 31905, Israel (972-4-8240196). Electronic mail may be sent to jlove@mathematica-mpr.com , lharrison@csu.edu.au , and sagi@psy.haifa.ac.i1 .
} 
A ccumulated evidence suggests that for children in child care, the quality of that care is important for their development (Lamb, 1998; Love, Schochet, \& Meckstroth, 1996), but findings differ with respect to the nature of the relationship of quality and quantity of care with various developmental outcomes. Although higher quality care has been associated with improved cognitive and language skills across a range of studies (e.g., see Campbell, Pungello, Miller-Johnson, Burchinal, \& Ramey, 2001; National Institute of Child Health and Human Development [NICHD] Early Child Care Research Network, 2000b, 2003b), associations between care quality and social-emotional development have been more mixed. The latest report from the NICHD Early Child Care Research Network (2003b), consistent with its previous reports, concludes that more time spent in "any of a variety of nonmaternal care arrangements" leads children to display more externalizing behavior problems, and that this relationship holds regardless of quality and other factors (NICHD Early Child Care Research Network, 2003a). Given the potential implications of such findings for understanding children's social-emotional development and contributing to child care policy, it is critical to assess the extent to which the NICHD findings might generalize to other child care contexts.

In this article, we bring together research on this issue from three perspectives: (a) the Sydney Family Development Project (SFDP), (b) the Haifa-NICHD merged data, and (c) the Early Head Start program evaluation in the United States. These perspectives contribute to the child care debate by extending the levels of observed child care quality beyond the more restricted range of the NICHD study, expanding the diversity of families included in the research and breaking the correlation between quality of care and socioeconomic status (SES) found in the NICHD study. The Haifa study adds a sample of families using much lower quality child care across all SES groups; the Australian study adds a sample of families from different SES groups using generally higher quality government-regulated care relative to the average quality of care in the United States; and the Early Head Start study adds a sample of low-income families experimentally offered care of higher quality than is generally available to families with infants and toddlers in the United States, and who are more diverse than the NICHD study families.
The child care settings of the three studies also exist within different regulatory contexts: both regulated (moderately high quality) and nonregulated settings in Sydney, homogenous but lower standards in Haifa, and homogenous and high standards in Early Head Start. The three studies include diverse measures of child care quality as well as a range of outcome measures that span children's cognitive and social-emotional domains (from attachment security to language to aggressive behavior problems).

Together our three perspectives capitalize on this diversity, and together they investigate how quantity and quality of child care may relate to children's development. We begin with the Sydney study, move to the merged Haifa-NICHD data, and then turn to the United States to look at child care in the federal Early Head Start program.

\section{An Australian Perspective on Quality, Quantity, and Stability in Child Care}

The first perspective is based on a 6-year longitudinal study of the use and effects of child care in an Australian sample of 147 primiparous mothers. Like the study conducted by the NICHD Early Child Care Research Network, the SFDP used a correlational design to assess the relationships of type, amount, and stability of children's child care experiences to developmental outcomes at key points: infant-mother attachment at 12 months, behavior problems at 30 months and 5 years, and teacher-rated adjustment to school at 6 years. The results, however, indicate a different relationship between child care and development than that reported by the NICHD study. We believe this is due, in part, to differing levels of child care quality in the Australian and U.S. contexts.

Like the United States, Australia has achieved a high level of workforce participation among women of child-bearing age $(46 \%$ with children under 5 years, Australian Bureau of Statistics, 1998; 65\% within 18 months after giving birth, Glezer, 1988); however, unlike the United States, this has been linked to government child care policies that have actively encouraged mothers to return to the workforce. Significant funds at both state and federal levels are directed to child care services for children from birth to 12 years, and to preschool programs for children aged 3 to 5 years. State regulations require child care centers to meet minimum child-staff ratios (e.g., New South Wales, 5:1 for children under 2 years, 8:1 for 
2-to 3-year-olds, 10:1 for 3-to 5-year-olds) and to employ specialist staff with early childhood qualifications (e.g., 3-to 4-year university degree, 2-to 3-year technical college diploma). Similar standards operate in Australian Family Day Care services, where the child-adult ratio is 5:1 for children under 5 years, and caregivers receive regular training and supervision by qualified early childhood staff. At the federal level, the Quality Improvement and Accreditation System requires centers to meet criterion-based standards of care for families to receive government subsidies for the cost of care (National Childcare Accreditation Council [NCAC], 1993). Fee reductions apply to most families, on an income-to-needs basis, and provide a major incentive for child care operators to become accredited. Australia's national system of formal, government-regulated child care services arguably achieves a uniformly higher level of quality than is found in the United States (e.g., Wangmann, 1995) and, accordingly, could be expected to show a different relationship with children's development than has been reported in studies in the United States.

Despite these provisions, however, not all child care is provided through the formal system, especially during the first 2 years of life, when informal care with relatives, friends, babysitters, or nannies is more typical (e.g., from birth to 1 year, 37\% informal vs. $8.5 \%$ formal; age 1 to 2 years, $46 \%$ informal vs. $24 \%$ formal; Australian Bureau of Statistics, 1999). Although similar informal arrangements have been noted in U.S. studies (NICHD Early Child Care Research Network, 1997a), the reasons may not be the same, perhaps because American parents do not receive government financial support for the full cost of child care and may choose informal care as a cheaper option (Scarr \& Eisenberg, 1993). Australian families are eligible for financial assistance, which suggests that the decision to use informal care arrangements may be based on personal preference rather than cost. In regard to quality, Australia requires informal child care providers to be registered but as yet has no regulatory systems to support or supervise caregivers. As a result, child-adult ratios, caregiver qualifications, and other factors potentially influencing quality are determined solely by the caregivers themselves. Without regulatory standards, informal settings are likely to be more variable in quality than are formal services and, therefore, less predictive of outcomes for children.
The informal and formal sectors of Australia's child care system provide a useful dichotomy for describing child care quality and comparing the effects of home-based care of variable quality with centers and Family Day Care homes of uniformly moderate to high quality. As such, Australian research has the capacity to extend what has been reported for quality versus quantity of child care in the NICHD study.

\section{Commonalities and Differences Between the SFDP and} the NICHD Study

Participants in the SFDP differed from those in the NICHD study in that all the SFDP children were firstborn, and mothers were selected to be representative of a larger community sample $(n=453)$ on broad indexes of personality functioning (see Harrison \& Ungerer, 2002a). The range of mothers' educational levels (less than high school to postgraduate) was comparable to the range in the NICHD sample (NICHD Early Child Care Research Network, 1997b).

Families' use of child care was similar to that of the NICHD families. By age 12 months, $72 \%$ of children were receiving regular nonmaternal care, $18 \%$ attended fewer than $10 \mathrm{hr}$ per week, 32\% attended part-time (11-30 hr per week), and 22\% attended fulltime (>30 hr per week). At 30 months, $86 \%$ were in regular care (24\% informal, $62 \%$ formal). By 3 years, $97 \%$ of children were in care, and many $(46 \%)$ had entered preschool. Cross-age correlations showed that average weekly hours during the first 12 months were consistent with weekly hours at 30 months, 3 years, and 4 years, $r s=.50$ to $.63, p<.001$.

Assessments of children's developmental outcomes matched those in the NICHD longitudinal study. We included security of infant-mother attachment at 12 months (Strange Situation; Ainsworth, Blehar, Waters, \& Wall, 1978), mother-reported behavior problems at 30 months and 5 years (Child Behavior Checklist [CBCL]; Achenbach, 1991), and teacher ratings of adjustment to school at 6 years. Teacher-child conflict was assessed (Student-Teacher Relationship Scale: Pianta, 1990) along with other measures of behavioral and social competence (Teacher-Child Rating Scale: Hightower et al., 1989; Classroom Behavior Inventory: Schaefer, Edgerton, \& Aaronson, 1978; Teacher Rating Form: Prosocial Behavior Scale: Klein \& Abu Taleb, 1993).

The SFDP research questions focused on quality (formal vs. informal care) and quantity of early child care (i.e., from birth to 30 months of age), and sta- 
bility of care over time (i.e., from birth to 6 years). Changes in care arrangements at three periods (birth to 12 months, 12 to 30 months, 30 months to 6 years) were used to construct a measure describing consistent patterns of more or less stable care. To assess the predictive relationships between child care factors and child outcomes, effects were assessed after controlling for family SES, maternal psychological wellbeing, marital relationship quality, social support, and child gender and temperament characteristics. For attachment security, maternal sensitivity also was included as a predictor (see Harrison \& Ungerer, 2002a). As the questions related to the experience of nonmaternal care, children who were in exclusive maternal are were not included in the analyses.

\section{Longitudinal Findings From the SFDP: Effects of Quality, Quantity, and Stability of Care}

Infant-mother attachment security at 12 months. Secure versus insecure attachment outcomes were compared for the 85 infants who received regular child care during the first year-52 in informal settings versus 33 in formal care. (Sixty children in maternal care were not included in these analyses.) Security was associated with formal care (Family Day Care: $100 \%$ secure; center care: $63 \%$ secure) rather than informal care (56\% secure). Of the children in part-time or full-time care, $70 \%$ had secure attachments, whereas only $39 \%$ of children attending care for fewer than $10 \mathrm{hr}$ per week were secure (Harrison \& Ungerer, 1997). The association between security and formal care was confirmed by logistic regression tests, controlling for hours of care, maternal education, social support, and child difficult temperament (Wald coefficient $=5.24, p=.02$; model $\chi^{2}=19.69, N=$ $85, d f=5, p=.001$; with maternal sensitivity, Wald coefficient $=3.53, p=.06$; model $\chi^{2}=23.87, N=78, d f=6$, $p=.001)$. Quantity of care was not a significant predictor in these analyses.

Behavior problems at 30 months and 5 years. Mothers' scores for the child's internalizing, externalizing, and total behavior problems at age 30 months and 5 years showed no associations with type or quantity of early care, $r \mathrm{~s}(115)=-.01$ to $.08, n \mathrm{~s}$.

Adjustment to school at 6 years. Teacher ratings provided a measure of teacher-child relationship conflict and summary ratings of children's social-emotional development (acting out, hostility, considerateness, prosocial behavior), personal adjustment (outgoing with peers, extrovert, shy or anxious, introvert), and adjustment to the learning demands of school (task orientation, creativity, intelligent behavior, distractibility). Relationships between child care factors and child outcomes were tested using hierarchical regression analyses, controlling for family and child characteristics (Harrison \& Ungerer, 2002b). Results showed that teacher- child conflict was associated with patterns of more unstable care over time $\left(\Delta R^{2}=.039, p<.05\right)$, but that it was not related to quantity or type of early care. Ratings of social-emotional adjustment were also related to stability of care $\left(\Delta R^{2}=.031, p<.05\right)$, being lowest in the group of children whose care had been consistently more unstable and highest in the group whose care had a more stable pattern. Personal adjustment ratings were higher when children had attended formal in contrast to informal care during the first 30 months $\left(\Delta R^{2}=.061, p<.01\right)$. Competence in learning was predicted by type of care (higher ratings for formal vs. informal care) and by quantity of care (lower ratings for longer hours of care), together explaining $6.3 \%$ of the variance (overall $R^{2}=.199, p<.01$ ).

\section{How and Why SFDP and NICHD Early Child Care Research Findings Differ}

Longitudinal results from the SFDP, based on teachers' and mothers' reports, provide a useful comparison with findings reported by the NICHD Early Child Care Research Network. Although there are many similarities between SFDP and NICHD children's experiences of care over time, the relationships of dimensions of care with developmental outcomes differ. We attribute this to different systems of child care provision and regulation. The present report from NICHD attributes poorer outcomes for social-emotional development to longer hours of care in general and, in particular, to more time in center-based care. In contrast, the SFDP study found no relationship between quantity of care and mother-reported problem behavior, social adjustment to school, or teacher-child conflict. Rather, it was stability of care over time that contributed to social-emotional aspects of development. Children who had experienced a consistent pattern of more changes in care were rated by teachers as having more conduct problems and less effective social skills. From an attachment perspective (Bowlby, 1969/1978), repeated changes of care, which place additional demands on children to form new relationships and create the stress of losing existing relationships, are a poor basis for developing emotional resourcefulness or so- 
cial competence. This may be especially salient as children make the transition to school, where they are required to adapt to large numbers of children and proportionally fewer adults than they experienced in child care.

Quality of care, described by formal, regulated care versus informal, unregulated care, was found to be an important predictor of child outcomes in the SFDP. Children who had attended formal settings before age 30 months (85\% of whom had received some center care) were rated by their school teachers as more outgoing and extroverted and less shy and anxious than children whose care had been in informal, nonregulated arrangements. Formal care was also associated with teachers' higher ratings for competencies in learning. These findings support a theoretical position that higher quality care (i.e., care programs that meet required standards for equipment, space, and programming, and are provided by appropriately qualified staff) will support children's learning and development (e.g., see National Association for the Education of Young Children, 1987; NCAC, 1993).

The SFDP results provided some evidence for the negative effects of longer hours of child care and, in this sense, were consistent with the NICHD report. Quantity of care was negatively associated with teachers' ratings for competence in learning, regardless of care type. (Note, however, that competence scores were highest for children who had attended formal care for fewer hours, and lowest for children receiving more hours of informal care.) Our results do not support the suggestion that behavior problems (linked to quantity of care) interfere with readiness to learn, but they indicate that problems of attention (task orientation, distractibility) and interest (creativity, intelligent behavior) were linked to longer hours of care.

\section{Quality of Child Center Care Is Important: A Mega-Analysis of the NICHD and the Haifa Study of Early Child Care}

\section{How Generalizable Is the NICHD Study?}

The present report by the NICHD Early Child Care Research Network (this issue) states that amount of early nonmaternal care-not quality of care-is the crucial predictor of later social-emotional adjustment. The main question is whether this finding pertains to the restricted quality range of nonmaternal care provisions in the United States, and to how generalizable it is to settings with much lower or much higher standards of care. Because the Haifa Study of Early Child Care was developed in parallel to the NICHD project and covered non-maternal care of much lower quality standards (Sagi, Koren-Karie, Gini, Ziv, \& Joels, 2002), we can now test the generalizability of some of the earlier NICHD findings in a broader range of quality standards by comparing and combining the two data sets.

\section{Commonalities and Differences Between the Haifa} and the NICHD Studies

Both the Haifa and the NICHD studies addressed questions concerning ecologically relevant predictors of social-emotional adjustment among infants who experienced various types and quality of early care, and in both studies, all SES groups were included. Because public child care centers in Israel are part of a nationwide network, however, infants from both lower-and middle-class families are placed in the same centers, whereas SES tends to be confounded with quality of group care in the United States. In both studies the investigators focused on mother characteristics, infant characteristics and development, mother-child interaction, mother-father relationship, the environment, and the structure and quality of various types of group care. Moreover, the samples are very large ( $N=1,153$, United States; $N=758$, Israel), with a low attrition rate and recruited in two different developed Western cultures, both of which place a high premium on education. A major outcome variable studied was quality of the infant-mother attachment (for more details on the U.S. study, see NICHD Early Child Care Research Network, 1997a; for more details on the Israeli study, see Sagi et al., 2002).

Various child care correlates were found in the NICHD study to neither adversely affect nor promote the security of infants' attachment to their mothers at the 15-month age point. However, certain child care conditions, in combination with certain home environments, did increase the probability that infants would be insecurely attached to their mothers. More specifically, infants who received poor quality of care, received more than $10 \mathrm{hr}$ of care per week, or were in more than one child care setting during the first 15 months of life were more likely to be insecurely attached only if their mothers were lower in sensitivity (NICHD Early Child Care Research Network, 1997a).

In the Haifa study, child care, especially center care, increased the likelihood of the infants' attachment insecurity to their mothers (Sagi et al., 2002). 
More specifically, a significantly larger proportion of insecure-ambivalent infants was found in center care $(46 \%)$ than in each of the following groups: family child care (28\%), paid individual care $(27 \%)$, individual care with a relative (19\%), and maternal care (26\%). Furthermore, the data clearly showed that it is the very high infant:caregiver ratio (average of 8:1) that accounted for this increased level of attachment insecurity among center care infants when compared with other professional care (viz., family or paid individual care). Because of the large sample size, it was possible to examine the sole effects of type and quality of care by controlling for a vast array of potentially intervening maternal and child characteristics in parallel with the NICHD study. None of these variables was found to mediate or to minimize the negative effects that were discovered only for center care. Thus, early infant center care in Israel, with its very high infant:caregiver ratio, challenged infants' security of attachment to their mothers.

In an additional analysis of the Haifa data (Aviezer, Sagi, \& Koren-Karie, in press), the expected link between maternal sensitivity and infant attachment security was found only for infants in individual care but not for infants in center care, despite the fact that mothers of children in individual care arrangements and mothers of children in center care were equally sensitive. This analysis suggests that the lack of associations between maternal sensitivity and infant attachment security might contribute to the lower security rates found for center care children. Thus, childrearing context may override the expected influence of maternal sensitivity. Indeed, in center care, the proportion of sensitive mothers with insecurely attached infants was similar to the proportion of insensitive mothers with insecurely attached infants, whereas the proportion of sensitive mothers with secure infants in individual care settings was significantly higher than the proportion of sensitive mothers with insecure infants. Hence, maternal sensitivity did not predict attachment security for center care children.

It should be noted that the moderating influence of center care on the formation of attachment relations in the Haifa study is different from the moderating effect of center care that was found in the NICHD study (NICHD Early Child Care Research Network, 1997a). In the NICHD study, maternal behavior was more salient for children in low-quality facilities of nonmaternal care, and the expected associations between maternal sensitivity and infant attachment were more emphasized. The Israeli data for children in low-quality nonmaternal care suggest that maternal behavior was less salient for these infants, who might be so overwhelmed by the low quality of the center care setting that they may no longer experience their mothers' child-rearing behavior as good enough.

Based on the structural characteristics of center care in the two studies (e.g., child-caregiver ratio), it is safe to conclude that center care in the Haifa study represented considerably lower quality of care (which was confirmed by direct observations) relative to center care in the NICHD Early Child Care Research Network (1997a; Sagi et al., 2002). In the NICHD study, the social structure as well as more defined state restrictions concerning certification of center care facilities may have prevented the researchers from investigating facilities with extremely low quality. Some child care facilities in deprived and dangerous inner-city areas may have been inaccessible to the researchers, and noncertified centers may have been hesitant to make themselves available for government-subsidized research. Although Israel is a developed Western country with a high education level, the early care system has received inappropriate public attention, resulting in a verylow-quality system of center care for infants. Thus, in combining the two studies for the purpose of secondary analyses, we create a broader continuum of quality of center care and thus make it less likely that restriction of range will influence the generalizability of the findings.

\section{A "Mega-Analysis" on Combined Data from the Haifa and NICHD Studies}

Combining data from the two studies, we focused on amount of care and child-caregiver ratio as important indicators of early care. Amount of care and child-caregiver ratio were defined identically in both studies (for details, see NICHD Early Child Care Research Network, 1997a; Sagi et al., 2002). Child-adult ratio is a distal index of quality of care. We were not able to use a more proximal assessment of quality of care here because the measure used in the NICHD study for assessing qualitative aspects in caregiverinfant interaction (Observational Record of the Caregiving Environment; ORCE) was a unique tool developed by the NICHD Early Child Care Research Network, which became accessible to the scientific community only at a later stage. The Haifa study had to develop its own quality assessments. In the Hai- 
fa study, however, child-caregiver ratio is strongly linked to quality of care (Koren-Karie, Sagi, \& EgozMizrachi, 1998; Sagi et al., 2002). Also, the NICHD Early Child Care Research Network (2000a) has recently found that positive caregiving was associated with smaller child-caregiver ratios. The NICHD study assessed positive caregiving in five types of care: centers, child care homes, and care provided by in-home sitters, grandparents, and fathers (it should be noted that in most publications the NICHD network presents paternal care as another type of nonmaternal care, in the same league as professional caregiving arrangements). Thus, child-caregiver ratio, which is a standard index in both the Haifa and the NICHD studies, is a useful index of quality of care in our secondary analysis. Our analyses on the combined Haifa and NICHD studies are restricted to infant-mother attachment as an outcome variable, and no data are available to conduct a longitudinal secondary data analysis with the combined sample.

\section{Summary of Major Findings}

The present analysis is based on a combined sample $(n=294)$ of all center care cases in both studies $(n=$ 143, United States; $n=151$, Israel). From Table 1 it can be derived that the child-caregiver ratio in the Haifa study was twice as large as the ratio in the NICHD study. In both studies, most infants were involved in center child care full time, with an average of about $5.5 \mathrm{hr}$ per week longer involvement in the Israeli case. In Israeli center child care, the percentage of securely attached infants was significantly lower (54\%) than in the NICHD centers (67\%). In the NICHD study as well as in the Haifa study, child-caregiver ratio and amount of care did not correlate significantly with attachment security (secure vs. nonsecure as a dichotomous variable). Only in the combined sample did we find a significant correlation between child-caregiver ratio and attachment security $(r=-.13, p<.05)$, indicating that a larger ratio was associated with less infant attachment security. Because amount of care was also significantly related to child-caregiver ratio, we included both predictors in a logistic regression on attachment security. In the combined sample, this regression proved to be significant $\left(\chi^{2}=6.02, n=267\right.$, $d f$ $=2, p=.049$ ). Only child-caregiver ratio contributed significantly to this regression equation (Wald coefficient $=4.09, d f=1, p=.043$ ). Amount of care did not significantly contribute to the logistic regression. In the separate NICHD and Haifa samples, the logistic regressions with amount of care and child-caregiver ratio did not significantly explain the variance in attachment security.

In a broader range of center care quality, we found that a higher child-caregiver ratio was indeed associated with less attachment security, whereas amount of care was not a significant predictor. In the separate NICHD and Haifa samples, a similar result failed to emerge. We suggest that the generalizability of the NICHD findings hinges on the specific context in which these results have been obtained, and on the resulting restriction of range for crucial variables. The NICHD finding of a small association between center care quality and child outcomes should be limited to the specific population of centers from which the NICHD study sample was derived - until empirically demonstrated otherwise. Although our findings in the combined sample are limited in time

Table 1

Description of the Separate NICHD and Haifa Center Care Samples, and the Combined Sample

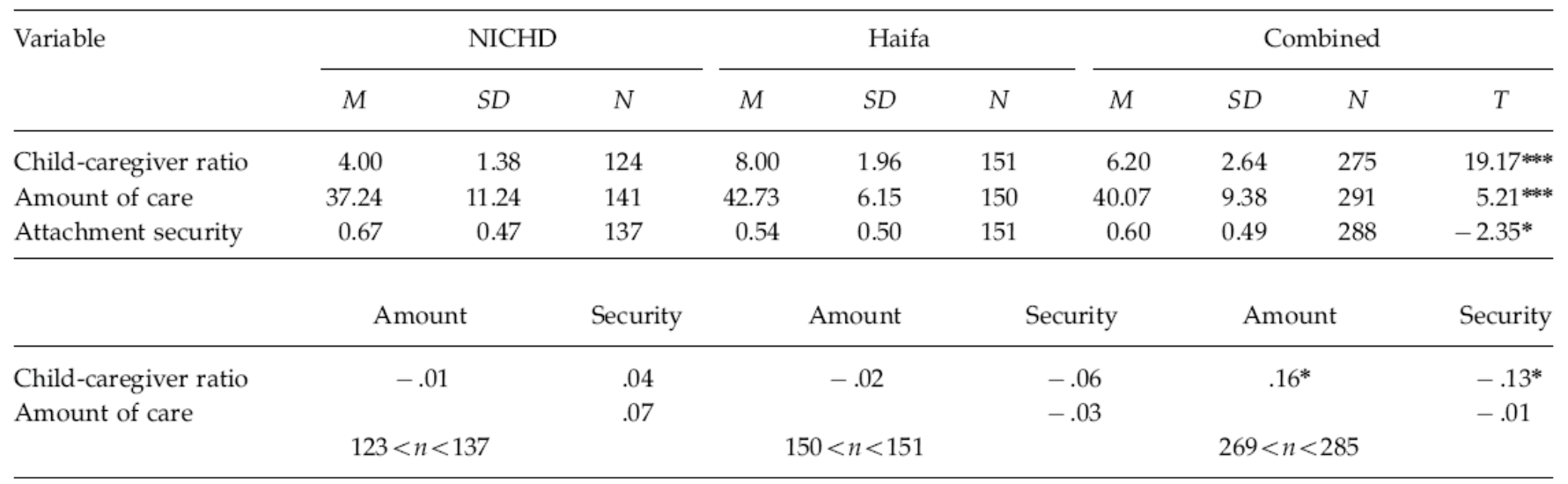

Note. NICHD is the National Institute of Child Health and Human Development.

$* p<.05$.

$* * * * 0.001$. 
(infancy) and in number and type of variables (childcaregiver ratio, amount of care, security of attachment), our case illustrates the risks of premature generalizations to other contexts, in particular when the causal processes leading to a significant association between quantity of care and child outcomes, such as security or aggression, still are obscure. Counterintuitive findings that are not based on a priori predictions from a theoretical framework should be interpreted with caution, although such findings may turn out to be among the most important and exciting in our field of inquiry. But let us first establish their truth value in other contexts and construct an adequate theoretical framework to account for them, before jumping to (policy) conclusions. The absence of evidence for a significant contribution of child care quality to children's social development, especially aggression, should be considered a finding in search of replication and explanation.

\section{Infant and Toddler Child Care in the Context of Early Head Start: Quantity, Quality, and Children's Development}

The third perspective on the effects of child care on children's development comes from the national evaluation of the federal Early Head Start program in the United States. Like the NICHD study, the Early Head Start evaluation examined the developmental progress of children during the first 3 years of life. Many of the children were in nonparental child care during those early years. In contrast to the NICHD study, however, the Early Head Start study focused exclusively on children from low-income families. Moreover, because of the Early Head Start intervention, many of the children received good-quality, center-based child care, which few of the NICHD children from low-income families experienced. Early Head Start was launched in 1995 by the Administration for Children and Families (ACF), in the U.S. Department of Health and Human Services and was designed as a two-generation program serving low-income pregnant women and families with infants and toddlers up to the age of 3. Early Head Start grantees design programs to achieve benefits for both children and their parents by providing home-or center-based child development services, combining these approaches, or implementing other locally designed options. Detailed findings about the programs' implementation (Administration for Children and Families [ACF], 2002b) and effects through age 3 (ACF, 2002a) can be found in the project's tech- nical reports, which also include detailed descriptions of the study design, instruments, data collection procedures, and analytic methods.

Important for the context of this research are the high standards the federal Head Start Bureau sets for child care quality. The Head Start Program Performance Standards established a clear set of expectations for the quality of center-based child development services. The standards require (a) a child-staff ratio of 4:1 and a maximum group size of eight infants and toddlers in center-based child care settings, and (b) child care staff to have a Child Development Associate credential within 1 year of being hired as an infant-toddler teacher (U.S. Department of Health and Human Services, 1996). These standards exceed those reported for the settings of the Australian and Israeli studies, as well as for standards set by most states within the United States, which is the context for the NICHD research.

\section{Method}

ACF selected 17 programs to participate in the national evaluation; these sites span all regions of the country and are in both urban and rural settings. A total of 3,001 families applying to these Early Head Start programs between July 1996 and September 1998 were randomly assigned either to the program or to a control group, which could access all services in the community except Early Head Start. Early Head Start families were diverse: $63 \%$ were Hispanic, African American, or other non-White groups; $48 \%$ had not earned a high school diploma; 38\% were teenage parents; and $23 \%$ were neither employed nor in school. Parent interviews and assessments of children's development were conducted when the children were approximately 14, 24, and 36 months old. Assessments when children were 24 months old included measures of cognitive development (the Bayley Scales of Infant Development Mental Development Index, BSID- MDI; Bayley, 1993), language development (the MacArthur Communicative Development Inventory language production scale, CDI; Fenson et al., 1993), and aggressive behavior (the Child Behavior Checklist, CBCL; Achenbach, 1992); see Administration on Children, Youth, and Families (2001, chap. 4) for details. At 36 months of age, child assessments included the BSID-MDI, the Peabody Picture-Vocabulary Test-Third Edition (PPVT-III; Dunn \& Dunn, 1997), and the CBCL aggressive behavior scale (Achenbach \& Rescorla, 2000; see ACF, 2002a, chap. 5). 
We asked parents about their use of child care (along with other services) at several points after program enrollment. Child care quality was assessed by trained observers in 2-to 3-hr visits to the child care settings children were in around the time that the 14-, 24-, and 36-month interviews were completed with the children's parents. Settings observed were those that children were in for at least $10 \mathrm{hr}$ per week for at least the 2 weeks preceding the interview and that were not in the child's own home (unless that in-home care was provided by a nonrelative). When children were 14 and 24 months old, observations of center-based care were conducted using the InfantToddler Environment Rating Scale (ITERS; Harms, Cryer, \& Clifford, 1990). When children were 36 months old, we used the Early Childhood Environment Rating Scale-Revised (ECERS-R; Harms, Clifford, \& Cryer, 1998). These scales consist of 35 items that assess the quality of care. (The shortened version of the ITERS we used excluded three items from the adult needs category-opportunities for professional growth, adult meeting area, and provisions for parents.) Item scores range from 1 to 7 , in which 1 is described as inadequate care, 3 as minimal care, 5 as good care, and 7 as excellent care. Child-teacher ratios and group sizes were also recorded.

\section{Findings: The Overall Impacts of Early Head Start on Children}

The national evaluation found that the program had favorable impacts on a wide range of outcomes for children (as well as their families). Early Head Start improved cognitive and language development of children at 24 and 36 months of age, with program children scoring significantly higher than control children on the BSID-MDI and the CDI or PPVT-III. (We are reporting only those program-control differences that were statistically significant in the regressionadjusted impact analyses that controlled for a large number of family background characteristics; see ACF, 2002a.) Early Head Start also produced favorable impacts on aspects of social-emotional development at 36 months, broadening the range of impacts on these behaviors that were found at 24 months. At both 24 and 36 months, levels of aggressive behavior were significantly lower for Early Head Start children than for control-group children.

At the time these positive program impacts were becoming manifest, most Early Head Start children were in regular child care arrangements, and child care use increased as the children got older. In the four center-based programs, for example, the percentage in some type of child care for at least $30 \mathrm{hr}$ per week increased from $66 \%$ at 14 months to $74 \%$ at 36 months. Moreover, Early Head Start increased the use of child care relative to the control group at all three ages by 7 to 10 percentage points (all differences significant at $p<.01$ ) and increased the percentage of children in good-quality care even more (see Table 2). Thus, the overall positive impacts of Early Head Start on children's development occurred while substantial numbers of children were enrolled in child care. (Details of the child care analyses described here can be found in a special policy report prepared by the authors; see ACF, 2003.)

The favorable impacts across a variety of dimensions of children's development cannot be attributed solely to the children's child care experiences, however, because not all children in Early Head Start were in child care settings. Furthermore, the Early Head Start intervention included family-and childdevelopment services, as described earlier, and the favorable overall impacts of this random-assignment study must be attributed to the full package of services received. Nevertheless, good-quality child care was an important aspect of the services received and thus is responsible for a share of the favorable impacts of the program.

Findings: The Contribution of Good-Quality Child Care to the Early Head Start Impacts on Children

We took two approaches to identifying the effects of good-quality child care on the development of Early Head Start children. Neither approach has the methodological strength of the overall random assignment design, but both suggest that, rather than doing harm, experience in good-quality child care can play a role in improving outcomes for children from economically disadvantaged families.

First, we focus on the four Early Head Start programs that offered full-day, full-year, center-based child development programs. Children typically attended these centers operated by Early Head Start for substantial periods each week, ranging from $51 \%$ at 24 months to $68 \%$ at 36 months attending for $30 \mathrm{hr}$ or more per week. (The children experienced even greater amounts of time in all types of nonparental care.)

The quality of child care in the four Early Head Start center-based programs was higher than is typical for center-based infant-toddler care in the United States, and for low-income children more specifically. Observational ratings showed that Early Head Start 
children at these sites were in classrooms that scored an average of 4.8 on the ITERS for 14-month-olds and 4.9 for 24 -month-olds. The classrooms scored 4.7 on the ECERS-R for 36-montholds. (Note that these averages for Early Head Start children include some children who, for a variety of reasons, were in community centers not operated by the program. Observations of all classrooms operated by Early Head Start centers across all sites showed a mean ITERS or ECERS-R rating of 5.0, 5.2, and 5.1 for 14-, 24-, and 36-month-old children, respectively.) The Early Head Start program quality was significantly higher than the quality that control group children experienced in the same communities. Control group children using center care in these communities were in classrooms rated significantly lower-an average of 3.8 to 3.9 for 14-and 24-month-olds on the ITERS, and 4.1 for 36-montholds on the ECERS-R (see Table 2). In addition, as Table 2 shows, child-adult ratios were 2.8 at 14 months, 3.2 at 24 months, and 5.6 at 36 months, again significantly better than ratios in classrooms attended by control group children. Early Head Start children in the four Early Head Start sites offering center-based child development services clearly received higher quality care as a result of their enrollment in the program.
Because of different measures, we cannot compare these quality ratings directly with the NICHD study classrooms, but national studies typically have found substantially lower ITERS scores than we observed in Early Head Start centers. The scores have ranged from 3.2 to 3.6 in infant and toddler classrooms in several sites across the United States (Cost, Quality, and Child Outcomes Study Team, 1995; Whitebook, Howes, \& Phillips, 1989).

The evaluation found that, when impacts on children's development were estimated separately by the program's approach to child development services, center-based programs were as effective as programs offering home-based or mixed-approach services (ACF, 2002a). This evidence certainly suggests that the large amount of good-quality center-based child care offered by Early Head Start was not detrimental to children and, indeed, contributed to positive outcomes found for the program as a whole.

Our second approach to the child care-child development link focuses on children in the Early Head Start program group who received center care. All children in this sample received the full Early Head Start intervention and were in center care during at least one of the three periods $(14,24$, or 36 months of age). The analyses relate child care quality and inten-

Table 2

Early Head Start Program and Control Group Differences in Child Care Use and Quality, by Age

\begin{tabular}{|c|c|c|c|c|c|c|}
\hline \multirow[b]{2}{*}{ Analysis } & \multicolumn{2}{|c|}{14 months } & \multicolumn{2}{|c|}{24 months } & \multicolumn{2}{|c|}{36 months } \\
\hline & Program & Control & Program & Control & Program & Control \\
\hline Percentage of all children in any child care arrangement & 66.4 & $56.5^{* *}$ & 60.5 & $51.3^{* *}$ & 84.4 & $77.7 * *$ \\
\hline$N$ & 997 & 916 & 820 & 749 & 715 & 608 \\
\hline Percentage of children in good-quality classrooms ${ }^{a}$ & 23 & $8 * *$ & 34 & $12 * *$ & 33 & $21 * *$ \\
\hline$N$ & 533 & 512 & 505 & 474 & 573 & 521 \\
\hline Percentage of children in good-quality classrooms in 4 center-based sites ${ }^{\mathrm{a}}$ & 26 & $9 * *$ & 37 & $12 * *$ & 35 & $16^{* *}$ \\
\hline$N$ & 268 & 252 & 256 & 224 & 254 & 211 \\
\hline $\begin{array}{l}\text { Percentage of children in classrooms that met Head Start performance } \\
\text { standards for child-adult ratios in } 4 \text { center-based sites }{ }^{\text {b }}\end{array}$ & 72 & $29 * *$ & 62 & $15^{* *}$ & 28 & $7 *$ \\
\hline$N$ & 268 & 252 & 256 & 224 & 254 & 211 \\
\hline Mean quality rating of centers used, at center-based sites ${ }^{c}$ & 4.8 & $3.9 * *$ & 4.9 & $3.8 *$ & 4.7 & $4.1 * *$ \\
\hline$S D$ & 1.0 & 1.3 & 1.0 & 1.2 & 1.0 & 1.3 \\
\hline$N$ & 168 & 52 & 162 & 48 & 153 & 72 \\
\hline Mean child-adult ratio in 4 center-based sites & 2.8 & $3.9^{* *}$ & 3.2 & $5.5^{* *}$ & 5.6 & $6.8^{* *}$ \\
\hline$S D$ & 1.0 & 1.7 & 1.1 & 2.6 & 3.0 & 2.7 \\
\hline$N$ & 102 & 45 & 159 & 47 & 152 & 72 \\
\hline
\end{tabular}

Note. From analyses conducted by Mathematica Policy Research and reported in The Role of Early Head Start Programs in Addressing the Child Care Needs of Low-Income Families With Infants and Toddlers: Influences on Child Care Use and Quality (Administration for Children and Families, 2003).

${ }^{a}$ Good quality is defined as Infant-Toddler Environment Rating Scale (ITERS) or Early Childhood Environment Rating Scale-Revised (ECERS-R) rating $\geqslant 5.0$ at all sites with sufficient observations. ${ }^{\text {b}}$ Head Start performance standards specify a child:staff ratio of $4: 1$ in groups no larger than 8 between birth and age $3 .{ }^{\circ}$ Quality is defined by ratings on the ITERS at 14 and 24 months of age and ECERS-R at 36 months. **Program-control difference significantly different, $p<.01$. 
sity at 14,24 , and 36 months to three key child outcomes at 24 and 36 months of age. Child care quality was measured by the ITERS or ECERS- R and by the child-adult ratio. Intensity was measured by average hours in center child care. We relate these measures of child care to children's cognitive development (BSID-MDI scores), language development (CDI at 24 months or PPVT-III at 36), and aggressive behavior (CBCL aggressive behavior problem scores). Using ordinary least squares regression analyses, mean child care quality and intensity scores at 14 and 24 months were used to predict 24-month outcomes, and mean quality and intensity scores at 14,24 , and 36 months were used to predict 36-month outcomes. All regression analyses controlled for child gender, child age at time of assessment, mother's race or ethnicity, mother's education and marital status, whether mother was teenage (under 19 years of age) at the time of the child's birth, and whether the site was urban.

Among the Early Head Start children who attended child care centers, those in higher quality center-based care showed enhanced developmental outcomes. Mean child care quality over time predicted higher scores on the 24-month BSID- MDI and 36-month PPVT-III. Mean child-adult ratio over time did not significantly predict child outcomes. Mean hours in center care over time predicted higher scores on the 24-and 36-month BSID-MDI and the 36-month PPVT-III. Neither the quality nor the amount of child care predicted child aggressive behavior at 24 or 36 months.

Consistent with previous research, these findings demonstrate that the quality of the child care centers that Early Head Start children attended was positively associated with children's cognitive and language development. Moreover, spending more time in center-based child care was associated with higher cognitive and language scores at 24 and 36 months. We found no evidence that more time in child care was associated with lower child wellbeing or higher rates of aggressive behavior (ACF, 2003).

\section{Summary and Conclusions}

This article has described three recent studies that examine associations between early child care and child outcomes among families who are different from those profiled in the NICHD Study of Early Child Care. The three studies suggest that quality of child care is an important factor influencing children's development and that quality may be an important moderator of the amount of time in care, particularly when the child care contexts differ from those of the NICHD research. Taken together, these studies point to a limited generalizability of the NICHD Early Child Care Research Network's findings. Although some of our results corroborate the NICHD study findings, other outcomes raise questions as to whether the associations between early child care quality and social-emotional development reported by the NICHD network would hold in a more diverse sample of children and families, and in a wider range of child care settings.

In the SFDP, children in care for longer periods before 30 months of age were rated lower by their teachers on adjustment to the learning demands of school at age 6, which appears consistent with the current NICHD finding that extensive early experience in child care may be associated with later behavior problems. In the SFDP, however, being in formal (i.e., higher quality) care was associated with higher ratings on learning competencies, suggesting that quality of care may balance the risk associated with time in care. In contrast to the NICHD report, social-emotional problems were related to stability rather than quantity of care. We suggest that, in a context in which standards for good-quality care are enforced through government regulatory mechanisms, the risk for behavior problems may be explained by factors other than time in care.

In the Haifa study, child care, especially center care, increased the likelihood of the infants' attachment insecurity to their mothers. We suggest that this is because early infant child care, with its very high infant-caregiver ratio, interfered with the traditional link often reported in the literature between maternal sensitivity and infants' security of attachment to their mothers. Analyses of the combined Haifa-NICHD data showed a significant association between child-caregiver ratio (as an index of quality) and children's attachment security but no relation between amount of care and attachment security. Contrary to the suggestion that, in the case of social-emotional development, only child care quantity matters, evidence was found for the significance of child care quality. We suggest that, when the range of quality of care is broadened-either upward or downward, as was the case in the combined Haifa-NICHD data set-quality of child care becomes more salient than time in care in influencing children's development. 
Finally, in the Early Head Start study, with its experimental design, children from low-income families (who would be expected to be at higher risk for behavior problems than those in the NICHD sample) experienced a wide range of positive impacts, including reduced aggressive behavior problems. These positive gains in cognitive, language, and social-emotional development occurred for children enrolled in a program that provided high levels of good-quality center child care. The experimental evidence raises serious questions about concluding that an increased amount of child care is detrimental for children's development, at least in the first 3 years of life. In addition, for the sample of Early Head Start children in center-based child care, spending more time in center-based child care was associated with higher cognitive and language scores at 24 and 36 months. We found no evidence that more time in child care was associated with higher rates of aggressive behavior problems. We suggest that this may be a function of both the sample characteristics (100\% low income) and the generally good levels of quality care the children experienced.

In summary, the three perspectives provided by our research provide strikingly consistent evidence for the importance of child care quality in the development of young children. We suggest that the generalizability of the NICHD study findings hinges on the specific context in which these results have been obtained. Our data stress the need to take into account the potentially restricted range for child care quality in each investigation. The NICHD Study of Early Child Care is the most impressive investigation on child care to date, and the consortium members should be highly commended for their careful, creative, and painstaking work on one of the most crucial issues in child development. Naturally, such seminal research triggers scientific debate, which underlines the importance of this unprecedented collaborative effort. We hope that the cumulative effect of the data reported here-collected in different countries, with different ranges of child care quality, in different regulatory contexts, and with a diversity of family characteristics - is to provide more complete estimates of the manner in which both quality and quantity of child care may influence a range of young children's developmental outcomes.

\section{References}

Achenbach, T. (1991). Manual for the Child Behavior Checklist/418 and 1991 profile. Burlington: University of Vermont.

Achenbach, T. M. (1992). Child Behavior Checklist for ages 2-3. Burlington: University of Vermont.

Achenbach, T. M., \& Rescorla, L. A. (2000). Manual for the ASE$B A$ preschool forms and profiles. Burlington: University of Vermont.

Administration for Children and Families (2002a). Making a difference in the lives of infants and toddlers and their families: The impacts of Early Head Start. Washington, DC: U.S. Department of Health and Human Services.

Administration for Children and Families (2002b). Pathways to quality and full implementation in Early Head Start. Washington, DC: U.S. Department of Health and Human Services.

Administration for Children and Families (2003). The role of Early Head Start programs in addressing the child care needs of low-income families with infants and toddlers: Influences on child care use and quality. Washington, DC: U.S. Department of Health and Human Services.

Administration on Children, Youth and Families. (2001). Building their futures: How Early Head Start programs are enhancing the lives of infants and toddlers of low-income families. Volumes I-II. Washington, DC: U.S. Department of Health and Human Services.

Ainsworth, M., Blehar, M., Waters, E., \& Wall, S. (1978). Patterns of attachment. Hillsdale, NJ: Erlbaum.

Australian Bureau of Statistics (1998). Australian social trends 1998. Canberra: Commonwealth of Australia.

Australian Bureau of Statistics. (1999). Child care, Australia, 1999. Canberra: Commonwealth of Australia.

Aviezer, O., Sagi, A., \& Koren-Karie, N. (in press). Ecological constraints on the formation of infant-mother attachment relations: When maternal sensitivity becomes ineffective. Infant Behavior and Development.

Bayley, N. (1993). Bayley Scales of Infant Development, second edition: Manual. New York: Psychological Corporation.

Bowlby, J. (1978). Attachment and loss: Vol. 1. Attachment. Middlesex, England: Penguin (Original work published 1969).

Campbell, F. A., Pungello, E. P., Miller-Johnson, S., Burchinal, M., \& Ramey, C. T. (2001). The development of cognitive and academic abilities: Growth curves from an early childhood educational experiment. Developmental Psychology, 37, 231-242.

Cost, Quality, and Child Outcomes Study Team (1995). Cost, quality, and child outcomes in child care centers; Public report. Denver: University of Colorado at Denver.

Dunn, L. M., \& Dunn, L. M. (1997). Peabody Picture Vocabulary Test-third edition. Circle Pines, MN: American Guidance Service. 
Fenson, L., Dale, P. S., Reznick, J. S., Thal, D., Bates, E., Hartung, J. P. et al. (1993). The MacArthur Communicative Development Inventories: User's guide and technical manual. San Diego, CA: Singular.

Glezer, H. (1988). Maternity leave in Australia: Employee and employer experiences: Report of a survey. Melbourne: Australian Institute of Family Studies.

Harms, T., Clifford, R., \& Cryer, D. (1998). Early Childhood Environment Rating Scale-Revised. New York: Teachers College Press.

Harms, T., Cryer, D., \& Clifford, R. (1990). Infant/Toddler Environment Rating Scale. New York: Teachers College Press.

Harrison, L., \& Ungerer, J. A. (1997). Child care predictors of infant-mother attachment security at age 12 months. Early Child Development and Care, 137, 31-46. Harrison, L. J., \& Ungerer, J. A. (2002a). Maternal employment and infantmother attachment security at 12 months postpartum. Developmental Psychology, 38, 758-773.

Harrison, L. J., \& Ungerer, J. A. (2002b, December). The Sydney Family Development Project: Family and child care predictors of school adjustment at age six. Paper presented in the symposium, Longitudinal Studies of Early Childhood in Australia, J. Bowes (Chair), at the Australian Association for Research in Education conference, Brisbane.

Hightower, A. D., Work, C., Cowen, E., Lotyczewski, B., Spinell, A., Guare, J., et al. (1989). The Teacher-Child Rating Scale: A brief objective measure of elementary school children's school behaviour and competence. School Psychology Review, 15, 393-409.

Klein, E. L., \& Abu Taleb, T. F. (1993, March). Self concept and prosocial behavior in kindergarten. Paper presented at the biennial meeting of the Society for Research in Child Development, New Orleans.

Koren-Karie, N., Sagi, A., \& Egoz-Mizrachi, N. (1998, July). Quality of infant group care in Israel. Paper presented at the biennial meeting of the International Society for the Study of Behavioral Development, Bern, Switzerland.

Lamb, M. E. (1998). Nonparental child care: Context, quality, correlates. In W. Damon, I. E. Sigel, \& K. A. Renninger (Eds.), Handbook of child psychology, volume 4: Child psychology in practice (5th ed., pp. 73-134). New York: Wiley.

Love, J. M., Schochet, P. A., \& Meckstroth, A. L. (1996). Are they in any real danger? What research does - and doesn't-tell us about child care quality and children's well-being. Princeton, NJ: Mathematica Policy Research.

National Association for the Education of Young Children. (1987). Accreditation criteria and procedures. Washington, DC: Author.

National Childcare Accreditation Council (1993). Putting children first. Quality Improvement and Accreditation System handbook. Sydney, Australia: Author.

National Institute of Child Health and Human Development Early Child Care Research Network (1997a). The effects of infant child care on infant-mother attachment security. Results of the NICHD study of early child care. Child Development, 68, 860-879.

National Institute of Child Health and Human Development Early Child Care Research Network (1997b). Familial factors associated with the characteristics of nonmaternal care for infants. Journal of Marriage and the Family, 59, 389408.

National Institute of Child Health and Human Development Early Child Care Research Network (2000a). Characteristics and quality of child care for toddlers and preschoolers. Applied Developmental Science, 4, 116-135.

National Institute of Child Health and Human Development Early Child Care Research Network (2000b). The relation of child care to cognitive and language development. Child Development, 71, 960-980.

National Institute of Child Health and Human Development Early Child Care Research Network (2001). Before Head Start: Income and ethnicity, family characteristics, child care experiences, and child development. Early Education and Development, 12, 545-576.

National Institute of Child Health and Human Development Early Child Care Research Network (2003a). Does amount of time spent in child care predict socioemotional adjustment during the transition to kindergarten? Child Development, 74, 976-1005.

National Institute of Child Health and Human Development Early Child Care Research Network. (2003b). Does quality of child care affect child outcomes at age $41 / 2$ ? Developmental Psychology, 39, 451-469.

Pianta, R. C. (1990). The Student-Teacher Relationship Scale. Unpublished manuscript, University of Virginia.

Sagi, A., Koren-Karie, N., Gini, M., Ziv, Y., \& Joels, T. (2002). Shedding further light on the effects of various types and quality of early child care on infant-mother attachment relationship: The Haifa study of early child care. Child Development, 73, 1166-1186.

Scarr, S., \& Eisenberg, M. (1993). Child care research: Issues, perspectives, and results. Annual Review of Psychology, 44, 613-644.

Schaefer, E., Edgerton, M., \& Aaronson, M. (1978). Child Behavior Inventory. Unpublished manuscript, Publisher: University of Carolina.

U.S. Department of Health and Human Services (1966, November). Head Start Program: Final rule. Federal Register, 61(215), 57186-57227.

Wangmann, J. (1995). Towards integration and quality assurance in children's services. Melbourne: Australian Institute of Family Studies.

Whitebook, M., Howes, C., \& Phillips, D. (1989). Who cares? Child care teachers and the quality of care in America: Final report: National Child Care Staffing Study. Berkeley, CA: Child Care Employee Project. 